\title{
ANÁLISE DA FREQUÊNCIA DA UTILIZAÇÃO DAS TÉCNICAS DE APRENDIZAGEM: UM ESTUDO COM DISCENTES DO CURSO DE CIÊNCIAS CONTÁBEIS
}

\author{
E. D. A. P. MEDEIROS* , C. L. L. MELO, E. R. F. C. V. LUCENA e Y. G. P. AZEVEDO \\ Universidade Federal do Rio Grande de Norte \\ erciliamedeiros@yahoo.com.br
}

Submetido 19/08/2016 - Aceito 11/06/2017

DOI: $10.15628 /$ holos.2017.4980

\section{RESUMO}

O presente trabalho tem como objetivo identificar a frequência de utilização de técnicas de estudo e aprendizagem pelos discentes do curso de Ciências Contábeis da Universidade Federal do Rio Grande do Norte (UFRN). A partir de uma amostragem não probabilística e acidental, composta por 231 discentes, buscou-se levantar a frequência de utilização das técnicas de estudo evidenciadas por Dunlosky et al. (2013) através da aplicação de questionários estruturados. Além da análise descritiva, agrupou-se os dados para determinar, através do teste de médias $t$ de Student, se há diferença estatística significativa entre as médias dos grupos: gênero, turno, vínculo de trabalho e período acadêmico. Os principais resultados demonstram que, de maneira geral, as técnicas mais bem avaliadas em relação à sua utilidade estão sendo
\end{abstract}

pouco adotadas, como a resolução de testes práticos e prática do estudo distribuído ao longo do tempo. Por outro lado, o grifo e sublinhado, além da releitura, consideradas estratégias de baixa utilidade, apresentaram ocorrência significativa. Em relação às estratégias de moderada utilidade, a auto explicação e o questionamento elaborativo demonstraram-se predominantes. Em síntese, a realização do teste de médias propiciou verificar que há diferença de médias no grupo gênero quanto às técnicas: resumos, grifo/sublinhado, releitura e testes práticos; no grupo turno de estudo quanto às técnicas questionamento elaborativo e testes práticos; e nos grupos vínculo empregatício e período de curso em relação à técnica de imagem mental.

PALAVRAS-CHAVE: Estratégias de Aprendizagem, Hábitos de Estudo, Educação em Ciências Contábeis.

\section{ANALYSIS OF THE FREQUENCY OF USE OF LEARNING TECHNIQUES: A STUDY WITH ACCOUNTING SCIENCES COURSE STUDENTS}

\begin{abstract}
The present study aims to identify the frequency of use of study and learning techniques by accounting students from the Federal University of Rio Grande do Norte (UFRN). From a non-probabilistic and accidental sampling, composed by 231 students, we sought to identify the frequency of use of study techniques evidenced by Dunlosky et al. (2013) by applying structured questionnaires. In addition to the descriptive analysis, we grouped the data to determine, through the test of average $t$ of Student, if there is a statistically significant difference between the means of groups: gender, shift, employment and academic period. The main results show that, generally, the techniques which are better evaluated for their utility are poorly adopted,
\end{abstract}

as the resolution of practical tests and the practice of distributing study over time. Otherwise, considered low utility strategies, italics and underlined, in addition to the rereading, showed significant occurrence. Regarding the moderate useful strategies, self explanation and elaborative question proved to be predominant. Briefly, the realization of average testing led to verify that there are average differences in gender group as the techniques: summaries, italics/underline, reinterpretation and practical tests; in the study turn group on elaborative questioning techniques and practical tests; and employment groups and course period in relation to the mental image technique.

KEYWORDS: Learning Strategies, Studying Habits, Accounting Education. 


\section{INTRODUÇÃO}

O Brasil tem presenciado mudanças significativas no âmbito da contabilidade, como a consolidação do processo de harmonização às normas internacionais de contabilidade (IFRS). Com essas mudanças, a objetividade, um pilar da contabilidade, cedeu lugar a subjetividade, tendo em vista que as normas emanadas do sistema contábil baseado em princípios buscam a melhor expressão da realidade econômica e financeira das entidades, necessitando assim, em determinados momentos, a utilização de estimativas no processo de mensuração e/ou evidenciação contábil (Paulo, Carvalho \& Girão, 2014).

Observa-se, então, que o atual contexto frequentemente demanda a utilização do juízo de valor do profissional contábil, bem como exige uma qualificação e atualização constante, face à transição para o padrão emitido pelo International Accounting Standard Board (IASB).

Além do ambiente empresarial, essas mudanças também afetaram o ambiente acadêmico das instituições de ensino superior, uma vez que, se a exigência sobre o profissional contábil aumentou, era esperada que a recíproca, a exigência em relação à qualidade do ensino nos ambientes formadores de profissionais, acompanhasse a mesma tendência. Nessa perspectiva, Oliveira e Oliveira (2013) descrevem que a busca pela excelência na qualidade do ensino é de interesse tanto dos alunos, a fim de se tornarem profissionais qualificados, quanto das instituições, para se manterem no processo evolutivo de transformação resultante da produção e difusão do conhecimento.

Tendo em vista a complexidade do processo de ensino-aprendizagem, Marion, Garcia e Cordeiro (1999) destacam que não só o método utilizado pelo professor é relevante para o processo, mas, também, a criatividade do docente e o conhecimento do perfil do seu alunado, para que este possa adequar seus métodos de ensino às características de aprendizagem dos estudantes. E, para a caracterização dos discentes, faz-se necessário o levantamento dos seus hábitos e estratégias de estudo.

Nesse sentido, Dunlosky, Rawson, Marsh, Nathan e Willingham (2013) se propuseram a analisar a eficácia de técnicas de aprendizagem, através da psicologia educacional e cognitiva. Os benefícios foram observados ao longo de quatro categorias de variáveis: condições de aprendizagem, características dos alunos, materiais e critérios das tarefas. Após uma extensa revisão de trabalhos publicados nesse campo, as técnicas foram classificadas como de alta, moderada ou baixa utilidade.

Os principais resultados do estudo de Dunlosky et al. (2013) foram que os testes práticos e a prática distribuída são consideradas técnicas de aprendizagem de alta utilidade, que o questionamento elaborativo, a auto explicação e a prática intercalada são técnicas de moderada utilidade, enquanto que os resumos, o grifo/sublinhado, a palavra-chave mnemônica, as imagens associadas a texto e a releitura são técnicas de baixa utilidade.

Considerando que os estudos sobre as estratégias de aprendizagem podem ser considerados umas das linhas de investigação mais proveitosas, desenvolvidas nos últimos anos 
no âmbito da aprendizagem, conforme evidenciado por Santos e Boruchovitch (2011), o principal objetivo desse trabalho é identificar a frequência de utilização de técnicas de estudo e aprendizagem pelos discentes do curso de ciências contábeis da Universidade Federal do Rio Grande do Norte (UFRN), com base nas técnicas de estudo evidenciadas por Dunlosky et al. (2013).

O presente estudo justifica-se pela importância da investigação das estratégias de aprendizagem utilizadas pelos estudantes universitários, conforme descrito por Marini e Boruchovitch (2014), bem como pela escassez de pesquisas que tratem diretamente das estratégias de aprendizagem, rotinas ou hábitos de estudos dos discentes universitários, principalmente os de ciências contábeis.

O presente trabalho está estruturado em cinco sessões. Na próxima seção, encontra-se o referencial teórico, que aborda aspectos relacionados às teorias e ao processo de aprendizagem, às estratégias de aprendizagem e hábitos de estudo, além dos estudos empíricos relacionados à área. A terceira apresenta a metodologia utilizada para a coleta e análise de dados, bem como as limitações da pesquisa. Na quarta tem-se a análise dos resultados obtidos, para, em seguida, na quinta parte, apresentar as considerações finais, onde foram evidenciadas as constatações do estudo, também apresentando sugestões para futuros trabalhos.

\section{REVISÃO BIBLIOGRÁFICA}

\subsection{Teorias de aprendizagem}

A aprendizagem tem sido tema de estudo em áreas distintas ao longo dos tempos, tanto em abordagem educativa quanto psicológica, assim como seu próprio significado. Perraudeau (2009) caracteriza aprendizagem como tudo o que reúne as atividades relacionadas a aprender, no sentido clássico de memorização, bem como àquelas a compreender, no que diz respeito à reflexão, raciocínio, criação, inovação, tomada de decisões.

Perraudeau (2009) afirma que, historicamente, pode-se elencar três modelos de aprendizagem: comportamentalista (tradicional), cognitivismo e construtivismo, tendo esses últimos surgido como contraponto ao primeiro.

O modelo comportamentalista (ou behaviorista) baseia-se no condicionamento como mecanismo da aprendizagem, num sistema de reforço positivo ou negativo, de exercícios de repetição, baseado na crença da reação direta do estudante frente a uma determinada situação. Mas, se por um lado, a repetição possibilita a construção de um referencial possível de ser acessado quando necessário, o condicionamento pode limitar a compreensão do aluno a situações idênticas, em vez da compreensão real e efetiva que possa ser extrapolada para contextos mais complexos (Perraudeau, 2009). Para Pozo (2002), os alunos treinados apenas para realizar exercícios fechados e rotineiros, dificilmente estarão preparados para tarefas mais abertas, que exijam soluções alternativas.

O cognitivismo, ainda segundo Perraudeau (2009), aborda a questão da aprendizagem a partir do planejamento da ação e do tratamento das informações coletadas. Seu interesse está 
voltado ao funcionamento do pensamento, por defender que esse pode determinar o comportamento, contrário ao postulado pelo primeiro grupo. $\mathrm{O}$ ensino leva em consideração a compreensão, a atenção, o raciocínio e o papel da memória.

O terceiro modelo, o construtivismo, também surge como uma crítica ao comportamentalismo. Nessa abordagem, o estudante assume papel ativo no processo de aprendizagem e o pensamento humano funciona como um conjunto de estruturas elaboradas durante o desenvolvimento, em processos de assimilação e acomodação. $O$ ensino deve ser conduzido de modo a descentrar o aluno para que esse possa construir novas respostas (Perraudeau, 2009).

\subsection{O processo de aprendizagem}

A maioria das teorias sobre aprendizagem tem em comum a premissa de um processo de aquisição de conhecimento e mudança de comportamento (Rabello, 2007). No desenvolvimento deste trabalho foi adotada a perspectiva cognitiva, segundo a qual a aprendizagem é um processo de aquisição do conhecimento, por meio do qual se incorporam novas representações à memória permanente ou se modificam as existentes (Pozo, 2002).

Dessa forma, Oliveira e Oliveira (2013) descrevem que a psicologia cognitiva fornece importantes informações sobre a necessidade de se conhecer e entender a individualidade de aprendizagem dos estudantes e ressalta a postura ativa que estes devem adotar no desenrolar do processo de aprendizagem.

De acordo com a psicologia cognitiva, suportada pela teoria do processamento da informação, a mente funciona como uma estrutura de processamento e armazenamento de informações e impressões recebidas do meio, sendo a aprendizagem concretizada no momento em que uma nova informação é armazenada (Oliveira, Boruchovitch \& Santos, 2009).

Para Pocinho (2010), os cognitivistas tomaram a direção dos estudos sobre os processos de memória e resolução de problemas, das formas complexas de aprendizagem, do "aprender a aprender e a pensar", do papel dos processos motivacionais e metacognitivos, das aprendizagens prévias e o uso de estratégias de estudo e de aprendizagem.

O autor também evidencia que a aprendizagem, num ambiente cognitivista, é encarada como um processo ativo e construtivo, desse modo, o processo de aprendizagem é o resultado de uma interação entre fatores contextuais e internos. Nessa perspectiva, Oliveira et al. (2009) descrevem que as estratégias de aprendizagem são recursos disponíveis no momento do estudo que muito contribuem para maximizar a recuperação e utilização imediata da informação previamente processada e armazenada.

\subsection{Estratégias de aprendizagem e hábitos de estudo}

Dentre os estudos empíricos relacionados às estratégias de aprendizagem e hábitos de estudo, Almeida (2002) elenca algumas das competências desejáveis que podem ser desenvolvidas para capacitar os alunos para os estudos: busca de informação complementar ou de 
aprofundamento, organização da informação, retenção de registros, estruturação dos ambientes de trabalho, comportamento e busca de apoios e de esclarecimento nos outros, hábitos de revisão de notas e de sistematização das matérias na preparação para testes.

O autor defende que essas habilidades podem ser desenvolvidas a partir de programas de treinos específicos, com o objetivo de prover uma série diversificada de procedimentos a serem acessados de acordo com as características das situações e das exigências das tarefas.

Vale ressaltar que esse treinamento de competências de estudo não deve ser encarado como um simples exercício técnico ou uma fórmula pronta para ser aplicada a qualquer tipo de aluno. Dessa maneira, identificou-se que o cerne da questão consiste em habilitar o estudante a escolher a estratégia, dentre uma gama de opções disponíveis, que seja mais apropriada às suas características pessoais e às tarefas a serem realizadas.

Além das diversas estratégias disponíveis, Fonseca, Sousa, Gouveia, Souza \& Gouveia (2013) afirmam que o desenvolvimento de hábitos torna a realização de tarefas um processo quase automático, permitindo sua execução com mais facilidade e rapidez. Para os autores, tais hábitos são tidos como uma habilidade que o aluno desenvolve para alcançar a realização de atividades de forma concentrada e persistente, possibilitando o indivíduo se manter atualizado, construindo saberes e adaptando as exigências de sua formação profissional.

Para Oliveira et al. (2009), estratégias de aprendizagem atuam como reforços na aprendizagem, possibilitando o desenvolvimento de atitudes de auto avaliação e a consequente melhora do desempenho escolar. Assim, o desenvolvimento de técnicas de aprendizagem e hábitos de estudos torna o processo mais eficiente. Na concepção de Ramírez (2008), o "aprender a aprender" se concentra na construção de um tipo de conhecimento específico, denominado estratégico, e não se resume apenas a utilizar técnicas e métodos de aprendizagem. $O$ estudante que faz uso de estratégias tem papel ativo e de mediador social do seu conhecimento.

Boruchovitch (1999) classificou as estratégias de aprendizagem em dois grandes grupos, cognitivas e metacognitivas. As primeiras são ferramentas de operação direta de informações e envolve os processos de organização, armazenamento e elaboração das mesmas. Para Boekaerts (1996), estratégias cognitivas são processos e comportamentos cognitivos desenvolvidos pelo estudante durante o processo de aprendizagem em si, com a finalidade de se realizar uma tarefa ou atingir um objetivo específico.

Por sua vez, as estratégias metacognitivas são recursos de planejamento, monitoramento e regulação do próprio pensamento. Boekaerts (1996) sugere que a performance metacognitiva se caracteriza por uma interação entre conhecimentos previamente adquiridos, armazenados nos diferentes níveis do repertório cognitivo. Tal interação é necessária para se traçar adequadamente os objetivos de aprendizagem e os planos de ação a serem empregados e, ainda, selecionar as estratégias cognitivas apropriadas em função dos objetivos estabelecidos, o contexto e das informações disponíveis.

Assim, o uso regular de estratégias metacognitivas favorece a obtenção de resultados mais satisfatórios, à medida que o aluno se torna mais consciente de seu papel e adota postura mais ativa, exercendo controle sobre sua aprendizagem de forma mais reflexiva (Oliveira et al., 2009). 
Ainda de acordo com os autores, o uso de estratégias metacognitivas de aprendizagem também permite que o aluno possa planejar, monitorar e regular o seu estudo de forma a potencializar o aprendizado.

A importância das técnicas de aprendizagem, tanto no desenvolvimento dessa autonomia quanto na aprendizagem mais efetiva, tem sido alvo de estudos e reconhecida pelos educadores (Boruchovitch, 1999). Nessa perspectiva, Boruchovitch (1993, como citado em Boruchovitch, 1999) descreve cinco tipos de estratégias de aprendizagem: ensaio, elaboração, organização, monitoramento e afetivas.

Estratégias de ensaio consistem na repetição ativa da informação a ser apreendida, seja de maneira escrita ou oral. Por sua vez, as de elaboração envolvem a criação de conexões entre o conhecimento a ser adquirido e aquele já existente (familiar), como analogias, resumos, criação de perguntas e suas respectivas respostas. Já as estratégias de organização estão relacionadas à imposição de estrutura ao material a ser aprendido, como diagramas para mostrar relações, rede de conceitos, topificar um texto.

As estratégias de monitoramento implicam que o estudante esteja constantemente consciente do quanto ele está sendo capaz de captar e absorver do conteúdo em questão e agir quando não estiver sendo satisfatório. Por fim, as estratégias afetivas, que consistem em eliminar qualquer sentimento desagradável não condizente com a aprendizagem. Requerem estabelecimento e manutenção de motivação e concentração, controle da ansiedade, planejamento apropriado de tempo e esforço, dentre outros aspectos.

Santos e Boruchovitch (2011) chamam a atenção para o fato das estratégias de aprendizagem serem formadas pelos elementos técnicas de aprendizagem e habilidades. Ou seja, seu domínio depende tanto das técnicas que a compõem quanto da habilidade do estudante em se utilizar delas, o que exige um uso reflexivo, não apenas mecânico.

As novas teorias de aprendizagem, de acordo com Almeida (2002), também salientam a importância do papel ativo do aluno, o que implica em assumir maior responsabilidade no processo de ensino-aprendizagem, desenvolvendo um comportamento de maior autonomia. Por isso, quanto mais o aluno se conhece como estudante, se tornando consciente de suas próprias características e habilidades, mais clareza terá em relação às tarefas que lhe são demandadas. Similarmente, à medida que o docente se torna conhecedor das características e estratégias de aprendizagem empregadas pelos seus alunos, mais eficiente será sua abordagem de ensino.

Apesar do grande número de definições de estratégias de aprendizagem encontradas na literatura especializada, Santos e Boruchovitch (2011) concordam que estas pressupõem uma sequência de atividades, operações ou planos orientados para a consecução das metas de aprendizagem e, desse modo, assumem características de um processo consciente e intencional. Portanto, considera-se necessário saber como, quando e por que utilizá-las, bem como controlar sua maior ou menor eficácia e modificá-la em função da tarefa, o que justifica o desenvolvimento de outros estudos nesse campo.

Visando identificar as estratégias de estudos utilizadas pelos estudantes de Ciências Contábeis, Carvalho (2013) verificou que os discentes da UFRN utilizam frequentemente técnicas 
como grifar ou destacar as partes consideradas importantes em um texto; fazer anotações em sala de aula e fazer perguntas ao professor no decorrer da aula. De acordo com o estudo, a elaboração de resumos nunca é utilizada ou é feita com uma frequência muito baixa por $50 \%$ dos alunos respondentes. Por outro lado, um grande número de alunos se utiliza da estratégia de escrever ou falar, usando as próprias palavras, sobre um assunto que acabou de estudar e discutem, com colegas de classe, as matérias que o professor abordou em sala de aula.

Também foi identificado que a consulta a outras referências e revisões periódicas dos assuntos estudados apresentaram uma frequência bem menor que as anteriores. Dentre os outros hábitos que apresentaram baixa ocorrência, citam-se: estudo em grupo e relacionar o conteúdo de uma disciplina com outra da mesma grade curricular, responder às questões ou exercícios que o professor solicitou para a aula seguinte, resolver questões além daquelas que o professor solicitou e refazer as questões que erraram na prova. Em síntese, foi observada uma baixa utilização das estratégias propostas para a verificação da aprendizagem.

Objetivando determinar a eficácia de técnicas de aprendizagem, Dunlosky et al. (2013) conduziram um estudo sob a perspectiva da psicologia educacional e cognitiva, a partir de extensa revisão de trabalhos publicados, a maioria referência nesse campo, analisando-se meticulosamente as técnicas investigadas por estes.

As técnicas foram classificadas como alta, moderada ou baixa utilidade. Para se chegar à recomendação sobre a utilidade relativa destas técnicas, foram avaliados seus benefícios gerais em quatro categorias de variáveis: condições de aprendizagem, características dos alunos, materiais e critérios das tarefas. As condições de aprendizagem incluem aspectos como ambiente de aprendizagem em que a técnica é implementada ou se aluno estuda sozinho ou com um grupo. Já as características dos alunos abrangem idade, capacidade e nível de conhecimento prévio. Por sua vez, os materiais variam desde conceitos simples para problemas matemáticos até textos científicos complicados. Os critérios das tarefas incluem diferentes medidas de resultados que são relevantes para o desempenho do aluno, como resolução de problemas e compreensão.

Em síntese, as técnicas de aprendizagem descritas por Dunlosky et al. (2013) estão demonstradas no Quadro 1. 
Quadro 1: Técnicas de aprendizagem

\begin{tabular}{|c|c|}
\hline Item & Descrição \\
\hline $\begin{array}{l}\text { Questionamento } \\
\text { elaborativo }\end{array}$ & $\begin{array}{l}\text { Produzir uma explicação para um fato ou conceito apresentado como } \\
\text { verdadeiro. }\end{array}$ \\
\hline Auto explicação & $\begin{array}{c}\text { Relacionar novas informações com outras já adquiridas ou procurar explicar } \\
\text { os passos adotados durante a resolução de problemas. }\end{array}$ \\
\hline Resumos & Elaborar resumos (de vários tamanhos) do material estudado. \\
\hline Grifo/sublinhado & $\begin{array}{c}\text { Grifar ou sublinhar trechos potencialmente importantes dos materiais a } \\
\text { serem aprendidos durante a leitura. }\end{array}$ \\
\hline $\begin{array}{l}\text { Palavra-chave } \\
\text { mnemônica }\end{array}$ & $\begin{array}{l}\text { Utilizar palavras-chaves e criar uma imagem para esta associando-a ao } \\
\text { material, escrito ou falado, a ser aprendido. }\end{array}$ \\
\hline $\begin{array}{l}\text { Imagens associadas a } \\
\text { textos }\end{array}$ & $\begin{array}{l}\text { Formar imagens mentais de materiais de texto a ser aprendido enquanto o } \\
\text { lê ou escuta. }\end{array}$ \\
\hline Releitura & Reler o material a ser aprendido. \\
\hline Testes práticos & $\begin{array}{l}\text { Realizar testes práticos (auto teste ou submetido por terceiros) sobre o } \\
\text { assunto a ser aprendido. }\end{array}$ \\
\hline Prática distribuída & $\begin{array}{l}\text { Utilizar um cronograma de distribuição das atividades de estudo ao longo do } \\
\text { tempo (em vez de concentrar tudo na véspera de um teste/prova). }\end{array}$ \\
\hline Prática intercalada & $\begin{array}{c}\text { Estabelecer um cronograma de estudos que mistura diferentes técnicas de } \\
\text { estudo, meios de abordar um problema, ou mistura diferentes tipos de } \\
\text { material, em uma mesma sessão de estudo. }\end{array}$ \\
\hline
\end{tabular}

Fonte: Adaptado de Dunlosky et al. (2013)

A seguir, serão descritas as técnicas de aprendizagem sintetizadas no Quadro 1 sob a perspectiva de Dunlosky et al. (2013), bem como seus achados para cada uma delas, incluindo sua recomendação sobre a utilidade.

A técnica chamada de questionamento elaborativo (elaborative interrogation) consiste na indagação, por parte dos alunos, ao serem apresentados a fatos tidos como verdadeiros, formulando respostas para o porquê desses fatos assim o serem. A técnica é eficiente por promover a integração de novas informações com outras já existentes, ajudando a organizar a informação nova, o que facilita a recuperação desse conhecimento quando demandado.

A avaliação dos autores foi de que essa técnica possui utilidade moderada, devido, principalmente, à falta de estudos que apontem sua eficácia geral em relação às quatro variáveis estabelecidas no início do estudo.

O segundo método estudado foi o de auto explicação (self-explanation), que corresponde a estabelecer relações entre novas informações com outras já adquiridas ou, ainda, procurar explicar os passos adotados durante a resolução de problemas. Os pontos fortes dessa técnica são sua aplicação a uma grande variedade de tarefas e conteúdos, necessidade de instruções mínimas e de pouca ou nenhuma prática anterior em auto explicação.

Entretanto, alguns alunos podem necessitar de mais instruções para serem bem-sucedidos no uso desse método, levando em consideração que estudos mostram que os resultados podem ser superiores se os estudantes forem ensinados a como implantar a estratégia com eficiência. Outro fator negativo está relacionado ao tempo consumido durante o processo. Por essas razões, a técnica foi avaliada apenas como de utilidade moderada. 
Em seguida, foi analisado o hábito de se fazer resumos do material estudado. Escrever resumos de textos a serem aprendidos é apontado como uma maneira de se identificar a essência e o que é importante no texto, em meio a uma grande quantidade de informações. Um ponto importante quanto à elaboração de resumos concerne à qualidade do material produzido, tendo em vista que se o aluno não conseguir enfatizar os pontos principais de um texto ou incluir informações incorretas, não se pode esperar benefícios para a aprendizagem e retenção.

De fato, estudos revisados por Dunlosky et al. (2013) mostraram ser verdadeira essa relação: resumos de maior qualidade contendo mais informações e relacionados a conhecimento prévio do assunto foram associados a melhor desempenho. No entanto, questionam a validade desta técnica quando há necessidade de treinamento antes de sua implementação, sobretudo em função do tempo requerido, quando poderiam ser adotadas outras técnicas que demandassem pouco ou nenhum treino prévio. Por essa razão, o método foi avaliado como de baixa utilidade.

Em análise a técnica de sublinhar ou grifar (highlighting and underlining) trechos considerados importantes em textos, foi identificado que o hábito é bastante comum, em virtude de sua simplicidade na utilização, não necessitando de treinamento, e por consumir pouco tempo além daquele necessário para uma simples leitura.

O uso desta técnica, embora comum, não encontra muito suporte na literatura. $\mathrm{O}$ modo como é normalmente utilizada mostra-se relativamente eficiente para memorização de fatos isolados, mas acaba por desfavorecer o resultado quando a tarefa envolve o uso de inferências que são estabelecidas ao se relacionar diferentes partes do texto. Por essa razão, o método foi avaliado como tendo baixa utilidade.

O método de associação de palavras-chaves a um determinado conteúdo e criação de imagem para associação ao material, escrito ou falado, é comumente utilizado no estudo de idiomas. No entanto, os benefícios de palavra-chave mnemônica podem ser estendidos a outras áreas: definições de palavras obscuras do vocabulário (pouco usadas, arcaicas, etc.), termos científicos, associações estado-capital, terminologia médica, dentre outras. Mas os defensores da técnica admitem que esta possa ser limitada a materiais para os quais seja mais propenso à criação de uma palavra-chave facilmente associável. Devido a essa reconhecida limitação, a técnica foi avaliada como de baixa utilidade.

A formação de imagens mentais de materiais de texto (imagery use for text learning) enquanto o lê ou escuta é considerada uma técnica benéfica ao estudante, à medida que o processo de desenvolver imagens aperfeiçoa sua organização mental, integrando informações do texto. Existem evidências de que o uso dessa estratégia pode melhorar a aprendizagem, no entanto, seus efeitos são limitados a materiais facilmente associáveis a imagens e apenas em testes de memória. Por esses motivos, a técnica foi avaliada como sendo de baixa utilidade.

Em relação à releitura (rereading), ou leitura adicional, evidencia-se que é uma das técnicas mais utilizadas por alunos enquanto estudam. São defendidas duas hipóteses para explicar o benefício desse método. Uma quantitativa, sugerindo simplesmente que se aumenta a quantidade de informação processada, sem levar em consideração o tipo ou nível de informação em questão. 
A outra hipótese é qualitativa, na qual a releitura permite a organização conceitual e o processamento das ideias principais do material estudado.

Como vantagens, cita-se que a técnica não requer treino, a não ser a orientação, bem como não demanda muito tempo de estudo, uma vez que as leituras subsequentes usualmente são mais rápidas que a primeira. Em contrapartida, as desvantagens surgem quando diretamente comparada a outras técnicas, como questionamento interrogativo, auto explicação e testes práticos. Além disso, a generalização dos benefícios não pode ser observada em todas as variáveis adotadas como critério de validação nesse estudo. Dessa maneira, a releitura foi avaliada como tendo baixa utilidade no processo de aprendizagem.

Em seguida, foram avaliados os resultados da realização de testes práticos como ferramenta de estudo. É sabido que existe certa aversão dos estudantes em relação a testes, principalmente porque esses estão associados a avaliações que compõem grande parte de suas notas no sistema educacional. No entanto, para fins de análise neste estudo, foram aplicados testes que não afetavam ou afetavam muito pouco suas notas ou, ainda, testes que os alunos poderiam desenvolver sozinhos, como aqueles que são apresentados ao fim de capítulos de livros e textos ou disponíveis eletronicamente como material suplementar.

As evidências sugerem que a realização desses testes aumenta a aprendizagem e a retenção de informação, sendo observado que nos testes práticos em que existe alguma resposta (feedback) aos alunos, estes apresentam resultados mais positivos, assim como testes mais curtos e mais frequentes. Dentre as vantagens listadas desse método de estudo, cita-se o tempo consumido e a desnecessidade de treinamento prévio. Por essas razões, a técnica foi avaliada como sendo de alta utilidade.

Os autores também analisaram a prática distribuída (distributed practice) de estudo. Em todos os níveis educacionais é comum a prática de concentração do estudo nos momentos que antecedem as avaliações sistemáticas. Entretanto, pesquisas suportam que a mesma quantidade de tempo de estudo, quando distribuída, gera resultados mais positivos em termos de retenção a longo prazo e aprendizagem. Uma das razões é que o estudo não é tão eficiente quando se dá em um intervalo de tempo pequeno em relação ao inicial, pois os alunos não demonstram tanto empenho ao recuperar informações pouco tempo após terem completado a mesma tarefa, induzidos pela falsa sensação de domínio do conteúdo.

No entanto, um aspecto negativo concerne à maioria dos livros e materiais existentes não encorajar a prática distribuída, tendo em vista que concentram assuntos relacionados e não revisam os conteúdos em unidades subsequentes. Considerando os aspectos positivos e negativos, Dunlosky et al. (2013) consideram a técnica da prática distribuída como tendo alta utilidade, havendo evidências de eficácia com uma grande variedade de características de estudantes e de materiais.

Por fim, os autores destacam ser comum que os alunos precisem aprender conteúdos de diferentes subtemas ou problemas de variados tipos, apresentando assim a prática intercalada de estudo (interleaved practice) na aprendizagem. O método consiste em diferentes técnicas de estudo e meios de abordar um problema, com vistas a auxiliar os alunos na distinção e 
comparação de diferentes tipos de problemas, promovendo um processo organizacional em que eles estejam mais propensos a usar o método de solução mais apropriado para cada um.

Ainda segundo Dunlosky et al. (2013), esse método favorece a memória de longo prazo. As pesquisas comparativas entre prática intercalada e estudo em bloco mostram que este último apresenta bons resultados quando os testes são realizados imediatamente, mas são significativamente melhores os do primeiro quando são testados algum tempo depois.

Em relação ao tempo consumido para essa técnica, observa-se que a solução de problemas se dá mais lentamente nessa prática, mas esse tempo adicional pode indicar outros processos ocorrendo simultaneamente, reforçando o aprendizado. No entanto, apesar dos resultados promissores, a prática intercalada foi avaliada como de moderada utilidade, principalmente pelo pouco número de trabalhos explorando o assunto.

Nessa perspectiva, os principais resultados da pesquisa de Dunlosky et al. (2013) evidenciam que os testes práticos e a prática distribuída são técnicas de alta utilidade, que o questionamento elaborativo, a auto explicação e a prática intercalada são consideradas técnicas de moderada utilidade, enquanto que o resumo, grifo e sublinhado, imagem mental de palavrachave, imagem mental de textos e releitura são elencadas como métodos de baixa utilidade.

\section{METODOLOGIA}

Este estudo pode ser classificado como uma pesquisa descritiva, quanto aos seus objetivos, de levantamento (survey), em relação a seus procedimentos, e quantitativa, na sua abordagem.

O procedimento de coleta de dados foi realizado por meio de questionários estruturados voltados aos alunos de Ciências Contábeis da UFRN. A aplicação se deu in loco e online, através de formulário abrigado no site Google Docs, em novembro de 2014. No total, foram respondidos 232 questionários, sendo que um foi preenchido por um estudante do curso de Direito e, por essa razão, excluído da análise. Desse modo, a amostra contou com 231 respondentes, conforme evidenciado na Tabela 1. O curso de Ciências Contábeis da UFRN possuía, no segundo semestre de 2014, 738 alunos ativos. Consequentemente, a amostra do estudo representa $31,30 \%$ do total do corpo discente.

Tabela 1: Participantes da pesquisa

\begin{tabular}{l|c|c}
\hline \multicolumn{1}{c|}{ Resposta } & Participantes & Percentual (\%) \\
\hline Pessoalmente & 91 & 39,4 \\
\hline Online & 140 & 60,6 \\
\hline Total & 231 & 100 \\
\hline
\end{tabular}

Fonte: Dados da pesquisa

A seleção dos participantes da pesquisa se deu por meio de uma amostragem não probabilística e acidental, por questões práticas. Apenas os alunos que estavam em sala de aula no momento da aplicação in loco e os respondentes do questionário online participaram da pesquisa. 
Em relação ao questionário, a parte inicial continha cinco quesitos sobre informações básicas dos respondentes para sua caracterização, como período, gênero, Índice de Rendimento Acadêmico (IRA), turno em que estuda e se possui vínculo empregatício ou de estágio. A segunda parte do questionário era formada por 10 quesitos relacionados ao objetivo principal de pesquisa, na qual os participantes deveriam responder com que frequência utilizam as técnicas de estudo listadas em cada item, usando, para isso, uma escala tipo likert, da seguinte forma: (1) nunca, (2) raramente, (3) às vezes, (4) frequentemente e (5) sempre.

As perguntas que compunham a última parte do instrumento de pesquisa listam as dez técnicas de estudo e aprendizagem com base em Dunlosky et al. (2013), que são: questionamento elaborativo; auto explicação; resumos; grifo/sublinhado; palavra-chave mnemônica; imagem mental; releitura; testes práticos; prática distribuída; e prática intercalada.

Após a sua obtenção, os dados foram tabulados no software de planilhas eletrônicas Microsoft Excel ${ }^{\circledR}$, onde foram analisados. Além da frequência das respostas, os dados foram agrupados para verificar se há diferença estatística significativa entre as médias dos grupos: gênero (masculino e feminino), turno (matutino e noturno), vínculo empregatício ou de estágio (se atuam ou não no mercado de trabalho) e período acadêmico $\left(1^{\circ}\right.$ ao $5^{\circ}$ e $6^{\circ}$ ao $\left.10^{\circ}\right)$. A análise foi feita pelo teste de médias $t$ de Student, com nível de significância $(\alpha)$ de $5 \%$. As seguintes hipóteses foram testadas utilizando os testes de médias: $\mathrm{H}_{0}=0$ (não há diferença estatística entre as médias dos grupos) e $\mathrm{H}_{1} \neq 0$ (existe diferença estatística entre as médias dos grupos).

Como limitação da pesquisa, ressalta-se o fato que diversos participantes não divulgaram, no perfil da amostra, a informação do índice de rendimento acadêmico, impossibilitando, assim, investigar a relação das técnicas e hábitos de estudos dos acadêmicos e o índice de rendimento acadêmico.

\section{RESULTADOS E DISCUSSÕES}

\subsection{Caracterização da amostra}

A primeira análise efetuada diz respeito ao perfil dos participantes da pesquisa, conforme descrito na Tabela 2.

Tabela 2: Caracterização dos participantes

\begin{tabular}{c|c|c|c}
\hline \multicolumn{2}{|c|}{ Item } & Quantidade & Resultado \\
\hline \multirow{2}{*}{ Turno } & Manhã & 128 & $55,41 \%$ \\
\cline { 2 - 4 } & Noite & 103 & $44,59 \%$ \\
\hline \multirow{2}{*}{ Gênero } & Feminino & 120 & $51,95 \%$ \\
\cline { 2 - 4 } & Masculino & 111 & $48,05 \%$ \\
\hline \multirow{2}{*}{$\begin{array}{c}\text { Vínculo de } \\
\text { trabalho }\end{array}$} & Sim & 154 & $66,67 \%$ \\
\cline { 2 - 4 } & Não & 77 & $33,33 \%$ \\
\hline \multirow{2}{*}{ Período } & 10 ao 50 & 120 & $51,95 \%$ \\
\cline { 2 - 4 } & 6o ao 10 & 111 & $48,05 \%$ \\
\hline
\end{tabular}

Fonte: Dados da pesquisa 
Os dados levantados foram agrupados da seguinte maneira: por turno de estudo (manhã e noite); por gênero (feminino e masculino); por vínculo empregatício ou de estágio (com vínculo e sem vínculo) e por período (do 1음 ao 5 ㅇ e do 6으 ao $10^{\circ}$ ), como podem ser observados na Tabela 2 .

Por turno de estudo tem-se o seguinte perfil: $44,59 \%$ estudam à noite e $55,41 \%$ pela manhã. Em relação a gênero, 120 participantes (51,95\%) se identificam com o gênero feminino e 111 (48,05\%) com masculino.

Entre os 231 estudantes, 66,67\% (154) relataram possuírem relação de trabalho ou estágio, enquanto 33,33\% (77) não possuem qualquer vínculo. A distribuição dos participantes em relação ao período em que se encontram é de $51,95 \%$ (120) entre o 1 ㅇ e o 5 o semestre de curso, enquanto que $48,05 \%$ (111) estão no segundo grupo, entre o 60 e o $10^{\circ}$ período.

\subsection{Análise das técnicas de estudo}

Os alunos foram questionados sobre a frequência de utilização das técnicas de estudo em análise nesta pesquisa. Os resultados estão evidenciados na Tabela 3.

Tabela 3: Frequência de utilização das técnicas de estudo

\begin{tabular}{c|c|c|c|c|c}
\hline \multirow{2}{*}{ Quesitos } & \multicolumn{5}{|c}{ Frequência } \\
\cline { 2 - 6 } & Sempre & Frequentemente & Às vezes & Raramente & Nunca \\
\hline 1 & $7,36 \%$ & $32,90 \%$ & $42,42 \%$ & $14,72 \%$ & $2,60 \%$ \\
\hline 2 & $15,58 \%$ & $36,80 \%$ & $40,26 \%$ & $6,93 \%$ & $0,43 \%$ \\
\hline 3 & $13,85 \%$ & $18,61 \%$ & $29,87 \%$ & $29,87 \%$ & $7,79 \%$ \\
\hline 4 & $33,77 \%$ & $32,03 \%$ & $18,18 \%$ & $11,69 \%$ & $4,33 \%$ \\
\hline 5 & $10,82 \%$ & $19,05 \%$ & $24,68 \%$ & $32,47 \%$ & $12,99 \%$ \\
\hline 6 & $13,85 \%$ & $20,35 \%$ & $38,10 \%$ & $18,18 \%$ & $9,52 \%$ \\
\hline 7 & $18,18 \%$ & $37,66 \%$ & $35,06 \%$ & $8,23 \%$ & $0,87 \%$ \\
\hline 8 & $5,63 \%$ & $18,61 \%$ & $38,96 \%$ & $27,71 \%$ & $9,09 \%$ \\
\hline 9 & $7,79 \%$ & $16,88 \%$ & $37,23 \%$ & $25,54 \%$ & $12,55 \%$ \\
\hline 10 & $4,33 \%$ & $16,02 \%$ & $29,00 \%$ & $34,20 \%$ & $16,45 \%$ \\
\hline
\end{tabular}

Fonte: Dados da pesquisa

A primeira questão tinha por objetivo verificar se alunos buscam elaborar explicações para fatos e conceitos usualmente aceitos como verdadeiros. A maioria dos respondentes afirmou utilizar-se dessa estratégia frequentemente $(32,90 \%)$ e às vezes $(42,42 \%)$, totalizando $75,32 \%$ dos alunos. Apesar da frequência elevada encontrada nesse estudo, essa técnica foi classificada no estudo de Dunlosky et al. (2013) como sendo de moderada utilidade.

A segunda questão objetivou determinar com que frequência os estudantes buscam relacionar novas informações com outras já adquiridas e explicar os passos adotados durante a resolução de problemas, técnica chamada de auto explicação. Foi observado que a maioria dos discentes declarou utilizar essa técnica sempre (15,58\%) e com frequência $(36,80 \%)$, totalizando $52,38 \%$ dos alunos, e $40,26 \%$ a usam às vezes. Essa estratégia também foi classificada como de moderada utilidade no estudo de Dunlosky et al. (2013).

A terceira questão buscou verificar se os alunos costumam elaborar resumos dos materiais estudados. Esse método, que foi avaliado no estudo de Dunlosky et al. (2013) como de baixa 
utilidade, não apresentou ocorrência no mesmo nível que as técnicas anteriores. A maioria respondeu que só costuma redigir resumos do material estudado às vezes $(29,87 \%)$ e raramente $(29,87 \%)$.

Já a questão de número quatro tinha como finalidade determinar a frequência com que os discentes destacam trechos importantes do material, seja pelo grifo ou pelo sublinhado. Os dados demostram que a maioria dos alunos adota essa técnica, avaliada como de baixa utilidade, sempre $(33,77 \%)$ e frequentemente $(32,03 \%)$, totalizando $65,80 \%$ dos respondentes.

Por sua vez, a quinta questão objetivou averiguar o uso de palavras-chave associadas a uma imagem relacionada ao material a ser aprendido. Apesar de alguns afirmarem utilizá-la às vezes $(24,68 \%)$ e frequentemente $(19,05 \%)$, totalizando $43,73 \%$, um número significativo afirmou usá-la raramente (32,47\%). Essa técnica foi avaliada no trabalho de Dunlosky et al. (2013) como sendo de baixa utilidade.

A sexta pergunta tinha por objetivo determinar se os alunos formam imagens mentais do texto a ser aprendido enquanto o leem ou escutam. Foi reportado por $38,10 \%$ dos participantes da pesquisa fazer uso desse método às vezes e frequentemente por $20,35 \%$, totalizando $58,45 \%$ dos respondentes. Essa técnica, no entanto, possui avaliação de baixa utilidade por Dunlosky et al. (2013).

A pergunta de número sete pretendia averiguar a frequência com que os alunos fazem a releitura do material a ser aprendido. Essa técnica se mostrou bastante popular entre os participantes do estudo: $18,18 \%$ a utilizam sempre, enquanto a maioria está distribuída na escala entre frequentemente $(37,66 \%)$ e às vezes $(35,06 \%)$, totalizando $90,90 \%$ da amostra. Apesar da alta frequência de utilização dessa técnica pelos discentes, é avaliada por Dunlosky et al. (2013) como de baixa utilidade.

Já a oitava pergunta teve por finalidade determinar se os estudantes realizam testes sobre o assunto a ser aprendido, seja por inciativa própria ou aplicados por terceiros. Essa estratégia de estudo, avaliada como sendo de alta utilidade por Dunlosky et al. (2013) é utilizada às vezes por $38,96 \%$ dos participantes dessa pesquisa e raramente por $27,71 \%$. Apenas $5,63 \%$ sempre realizam testes práticos do conteúdo estudado.

Na sequência, a pergunta nove se destinava a averiguar qual a frequência com que os alunos distribuem os momentos de estudo em um cronograma planejado em vez de concentrá-los nos períodos que antecedem as avaliações. Esse método, assim como o anterior, é considerado de alta utilidade, mas, assim como a realização de testes, não é tão frequente na nossa amostra. Verificou-se que $37,23 \%$ dos participantes às vezes distribuem seus estudos ao longo do tempo, $25,54 \%$ o fazem raramente e somente $7,79 \%$ sempre adotam um cronograma de práticas de estudo.

A décima pergunta teve como finalidade determinar se os discentes adotam a prática intercalada de estudos. Os dados coletados demonstram que essa estratégia também não é tão frequentemente utilizada pelos discentes participantes no estudo. De fato, 34,20\% afirmaram que raramente a utilizam e $16,45 \%$ nunca a utilizam, enquanto que $29,20 \%$ às vezes intercalam 
materiais e práticas de estudo. Essa técnica foi classificada no estudo de Dunlosky et al. (2013) como de baixa utilidade.

\subsection{Análise de frequência das técnicas e sua classificação}

Para determinar quais técnicas são utilizadas com maior frequência, foram computados os percentuais dos participantes que afirmaram utilizá-las na escala sempre e frequentemente.

Tabela 4: Frequência de utilização das técnicas analisadas

\begin{tabular}{c|c|c}
\hline Técnica & Frequência & Classificação \\
\hline Grifo/sublinhado & $65,80 \%$ & Baixa \\
\hline Releitura & $55,84 \%$ & Baixa \\
\hline Auto explicação & $52,38 \%$ & Moderada \\
\hline Questionamento elaborativo & $40,26 \%$ & Moderada \\
\hline Imagem mental & $34,20 \%$ & Baixa \\
\hline Resumos & $32,46 \%$ & Baixa \\
\hline Palavra-chave mnemônica & $29,87 \%$ & Baixa \\
\hline Prática distribuída & $24,67 \%$ & Alta \\
\hline Testes práticos & $24,24 \%$ & Alta \\
\hline Prática intercalada & $20,35 \%$ & Moderada \\
\hline
\end{tabular}

Fonte: Dados da pesquisa

Como se pode observar, as técnicas mais comumente empregadas pelos participantes deste estudo foram as de grifar e sublinhar textos, a releitura do material a ser aprendido e auto explicação, o ato de relacionar novas informações com outras já adquiridas e a reflexão sobre os passos adotados na resolução de problemas, todas utilizadas com frequência por mais de $50 \%$ dos respondentes. Dentre essas, somente a última recebeu uma avaliação positiva no estudo de Dunlosky et al. (2013), sendo classificada como tendo moderada utilidade.

Por outro lado, as estratégias consideradas como de alta utilidade, a prática distribuída e a resolução de testes práticos, são adotadas frequentemente por menos de $25 \%$ dos discentes entrevistados. E a prática intercalada, de moderada utilidade, é utilizada por apenas $20,35 \%$ dos participantes.

\subsection{Análise da hipótese de pesquisa}

A fim de se testar a hipótese de pesquisa $\mathrm{H}_{0}$ : não existe diferença estatística entre as médias dos grupos, utilizou-se o teste de médias $t$ de Student, com nível de significância de $5 \%$. Os respondentes foram separados por gênero, turno, vínculo de trabalho e período acadêmico, conforme descrito na Tabela 5.

Tabela 5: Análise da hipótese de pesquisa

\begin{tabular}{c|c|c|c|c}
\hline Técnicas & Gênero & $\begin{array}{c}\text { Turno de } \\
\text { estudo }\end{array}$ & $\begin{array}{c}\text { Vínculo de } \\
\text { trabalho }\end{array}$ & $\begin{array}{c}\text { Período } \\
\text { acadêmico }\end{array}$ \\
\hline Questionamento & 0,3985 & 0,0313 & 0,5686 & 0,3696 \\
\hline
\end{tabular}




\begin{tabular}{c|l|l|l|l}
\hline elaborativo & & & & \\
\hline Auto explicação & 0,9743 & 0,0613 & 0,2076 & 0,2096 \\
\hline Resumos & 0,0002 & 0,1146 & 0,2163 & 0,9134 \\
\hline Grifo/sublinhado & 0,0000 & 0,1853 & 0,1171 & 0,9713 \\
\hline Palavra-chave mnemônica & 0,6384 & 0,7652 & 0,1124 & 0,8452 \\
\hline Imagem mental & 0,5679 & 0,4104 & 0,0163 & 0,0282 \\
\hline Releitura & 0,0270 & 0,5575 & 0,0990 & 0,1689 \\
\hline Testes práticos & 0,0351 & 0,0222 & 0,3851 & 0,5921 \\
\hline Prática distribuída & 0,1576 & 0,1104 & 0,3756 & 0,2450 \\
\hline Prática intercalada & 0,1825 & 0,0597 & 0,3212 & 0,1525 \\
\hline
\end{tabular}

Fonte: Dados da pesquisa

Ao analisar os p-values evidenciados na Tabela 5, observa-se que as práticas de questionamento elaborativo, auto explicação, palavra-chave mnemônica, imagem mental, prática distribuída e prática intercalada não apresentaram diferenças estatisticamente significativas entre os respondentes do gênero feminino e masculino, tendo em vista que os $p$-values $>0,05$. Dessa forma, não rejeita-se a $\mathrm{H}_{0}$ para o gênero, em relação às técnicas descritas anteriormente.

No entanto, percebe-se que os $p$-values das técnicas de estudo: resumo, grifo/sublinhado, releitura e testes práticos apresentaram-se inferior ao nível de $5 \%$ de significância, demonstrando que os homens e as mulheres possuem diferentes frequências de utilização destas técnicas, rejeitando-se, assim, a $\mathrm{H}_{0}$.

No tocante ao turno de estudo, apenas as frequências médias de utilização das técnicas de questionamento elaborativo e de testes práticos apresentaram diferenças estatisticamente significativas, considerando que os $p$-values encontram-se abaixo do nível de significância de 5\%, devendo-se, assim, rejeitar a $\mathrm{H}_{0}$ para estas técnicas.

Observa-se, também, que as técnicas de estudo: questionamento elaborativo, auto explicação, resumos, grifo/sublinhado, palavra-chave mnemônica, releitura, testes práticos, prática distribuída e prática intercalada apresentaram-se significantes, ao nível de 5\%, para os grupos vínculo de trabalho e período acadêmico, demonstrando que não há diferença de médias entre a utilização das técnicas de estudo descritos anteriormente.

Por conseguinte, apenas a técnica imagem mental apresenta diferença significativamente estatística, tendo em vista que o $p$-value $<0,05$. Dessa forma, a $\mathrm{H}_{0}$ é rejeitada, evidenciando a divergência de frequência de utilização da técnica imagem mental tanto entre os respondentes que possuem vínculo de trabalho e os que não possuem, quanto para os que estão cursando do $1^{\circ}$ ao $5^{\circ}$ período e os que estão entre o $6^{\circ}$ e o $10^{\circ}$.

Em síntese, observa-se que há diferença de médias entre os gêneros quanto às técnicas: resumos, grifo/sublinhado, releitura e testes práticos; entre os respondentes que estudam pela manhã e à noite, em relação à frequência de utilização das técnicas questionamento elaborativo e testes práticos; assim como entre os respondentes dos grupos vínculo empregatício e período de curso quanto à frequência de utilização da técnica de estudo imagem mental, evidenciando-se que ambos possuíram resultado convergente. 


\section{CONCLUSÃO}

O presente estudo teve como objetivo identificar a frequência de utilização de técnicas de estudo e aprendizagem pelos discentes do curso de Ciências Contábeis da UFRN, através da aplicação questionários elaborados com base no estudo de Dunlosky et al. (2013). Os questionários aplicados foram do tipo estruturado, sendo aplicado à 231 discentes durante o período de Novembro de 2014.

Além de verificar a frequência de utilização das técnicas de estudo, utilizou-se o teste de médias $t$ de Student para identificar se havia diferença estatisticamente significativa entre os grupos: gênero, turno, vínculo de trabalho e período acadêmico.

Verificou-se que as estratégias mais comumente utilizadas pelos alunos em geral foram avaliadas como de pouca utilidade no processo de aprendizagem, tendo em vista que as estratégias mais frequentes entre os participantes foram o grifo e sublinhado e a releitura. Em contrapartida, observou-se a pouca utilização daquelas que foram mais positivamente recomendadas, a resolução de testes práticos e a prática do estudo distribuído ao longo do tempo.

Entre as estratégias consideradas de moderada utilidade, a auto explicação e o questionamento elaborativo obtiveram resultados satisfatórios, sendo utilizadas por 52,38\% e $40,26 \%$ dos respondentes, respectivamente. Já a prática intercalada foi relacionada apenas por $20,35 \%$ dos participantes.

Quando comparadas as respostas sobre a utilização das técnicas de estudo por grupos estudados (gênero, turno, vínculo de trabalho e período), algumas diferenças puderam ser observadas, tendo em vista a diferença de médias entre os gêneros quanto às técnicas: resumos, grifo/sublinhado, releitura e testes práticos, rejeitando-se, assim, a $\mathrm{H}_{0}$.

Também observou-se que a $\mathrm{H}_{0}$ também foi rejeitada para os respondentes que estudam pela manhã e à noite, em relação à frequência de utilização das técnicas questionamento elaborativo e testes práticos; assim como entre os respondentes dos grupos vínculo empregatício e período de curso quanto à frequência de utilização da técnica de estudo imagem mental, evidenciando-se que ambos possuíram resultado convergente.

Em síntese, a subutilização das técnicas de estudos consideradas de alta utilidade entre os alunos participantes da pesquisa indica a necessidade de estudos mais aprofundados. Especialistas sugerem que, à medida que os alunos descobrem mais sobre eles como estudantes e desenvolvem a prática da reflexão sobre o estudo, hábitos e estratégias adotadas, mais eficaz será seu processo de aprendizagem.

Essas informações podem, também, auxiliar o docente no planejamento de sua prática, na escolha do material a ser utilizado, na metodologia a ser aplicada. E existe, ainda, uma lacuna de pesquisas que relacionem as técnicas e hábitos de estudos ao desempenho acadêmico, o que não foi possível de se realizar nesse trabalho pela relutância de alguns participantes em informar seu índice de rendimento acadêmico. Outro passo a ser adotado em futuras pesquisas é a inclusão de alunos de outros cursos do ensino superior, expandindo-se a outras áreas de conhecimento. 


\section{REFERÊNCIAS}

Almeida, L. S. (2002). Facilitar a aprendizagem: ajudar os alunos a aprender e a pensar. Psicologia Escolar e Educacional, 6(2), pp. 155-165.

Boekaerts, M. (1996). Self-regulated learning at the junction of cognition and motivation. European Psychologist, 1(2), pp. 100-112.

Boruchovitch, E. (1999). Estratégias de aprendizagem e desempenho escolar: considerações para a prática educacional. Psicologia: Reflexão e Crítica, 12(2), pp. 361-376.

Carvalho, P. H. C. (2013). Análise das estratégias de estudo utilizadas pelos discentes do curso de ciências contábeis da Universidade Federal do Rio Grande do Norte. Monografia, Universidade Federal do Rio Grande do Norte, Natal, RN, Brasil.

Dunlosky, J., Rawson, K. A., Marsh, E. J., Nathan, M. J., \& Willingham, D. T. (2013). Improving students' learning with effective learning techniques: promising directions from cognitive and education psychology. Association for Psychological Science, 14(1), pp. 4-58.

Fonseca, P. N., Sousa, D. M. F., Gouveia, R. S. V., Souza, J. F., Filho, \& Gouveia, V. V. (2013). Escala de hábitos de estudo: evidências de validade de construto. Avaliação Psicológica, 12(1), pp. 71-79.

Marini, J. A. S., \& Boruchovitch, E. (2014). Estratégias de aprendizagem de alunos brasileiros do ensino superior: considerações sobre adaptação, sucesso acadêmico e aprendizagem autorregulada. Revista Eletrônica de Psicologia, Educação e Saúde, 1, pp. 102-126.

Marion, J. C., Garcia, E., \& Cordeiro, M. (1999). A discussão sobre a metodologia de ensino aplicável à contabilidade. Revista do Conselho de Contabilidade de São Paulo, 10(1), pp.28-33.

Oliveira, K. L., Boruchovitch, E., \& Santos, A. A. A. (2009). Estratégias de aprendizagem e desempenho acadêmico: evidências de validade. Psicologia: Teoria e Pesquisa, 25(4), pp. 531536.

Paulo, E., Carvalho, L. N. G., \& Girão, L. F. A. P. (2014). Algumas questões sobre a normatização contábil baseada em princípios, regras e objetivos. Revista Evidenciação Contábil \& Finanças, 2(2), pp. 24-39.

Perradeau, M. (2009). Estratégias de aprendizagem: como acompanhar os alunos na aquisição dos saberes. Porto Alegre: Artmed.

Pocinho, M. M. F. D. D. (2010). Psicologia, cognição e sucesso escolar: concepção e validação dum programa de estratégias de aprendizagem. Psicologia: Reflexão e Crítica, 23(2), pp. 362-373.

Pozo, J. I. (2002). Aprendizes e mestres: a nova cultura da aprendizagem. Porto Alegre: Artmed.

Rabello, C. R. L. (2007). Aprendizagem na educação à distância: dificuldades dos discentes de licenciatura em ciências biológicas na modalidade semipresencial. Dissertação de mestrado, Universidade Federal do Rio de Janeiro, Rio de Janeiro, RJ, Brasil. 
Ramírez, A. V. (2008). La adquisición de hábitos como finalidad de la educación superior. Educación y Educadores, 11(1), pp. 167-180.

Santos, O. J. X., \& Boruchovitch, E. (2011). Estratégias de aprendizagem e aprender a aprender: concepções e conhecimento de professores. Psicologia: Ciência e Profissão, 31(2), pp. 284295. 